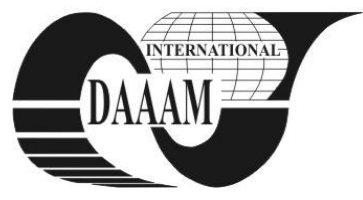

Annals of DAAAM for 2011 \& Proceedings of the 22nd International DAAAM Symposium, Volume 22, No. 1, ISSN 1726-9679 ISBN 978-3-901509-83-4, Editor B. Katalinic, Published by DAAAM International, Vienna, Austria, EU, 2011 Make Harmony between Technology and Nature, and Your Mind will Fly Free as a Bird

\title{
NEW APPROACH OF ERGONOMICS WORKPLACE DESIGN
}

\author{
MICIETA, B[ranislav]; DULINA, L[uboslav] \& SMUTNA, M[artina]
}

\begin{abstract}
Authors of this article to tackle solving the ergonomic design of workplaces, closely with the research team of Central European Institute of Technology (CEIT). Together, in addition ergonomics and detailed design of workstation devoted to the digitization using $3 D$ laser scanning, $3 D$ design of production systems, planning processes, development and analysis of time management, simulation and optimization of production and logistics systems. Based on its research was developed, after verification of the implemented solutions in the industry, has already begun using their own progressive approach to a detailed design of workplaces using elements of the concept of digitization and digital enterprise called CEIT ErgoDesign, which is presented in this paper.

Key words: ergonomics, digital tools, workplace design, health, assembly
\end{abstract}

\section{INTRODUCTION}

Improving the performance of assembly processes brings a lot of pressure on the physical and mental qualities, which is closely related to quality production and productivity of work (Hatiar, 2008). Processes should be designed to allow operators the fastest and highest quality performance of the required operations. A prerequisite for such work is properly ergonomically designed workstation. For industrial enterprises are the interesting solutions that quickly and with minimal disruption to the existing production will bring the desired improvements. Methods for evaluation of the workplace and the load of operators are now largely controlled and well applicable, as we have good data input. Experience of the implemented solutions in the industry has shown that the problem resides collection of high quality data input and verification of the proposed predictive solutions that are key to a successful project.

\section{A PROGRESSIVE APPROACH OF DETAILED ERGONOMIC DESIGN WORKPLACES}

The primary idea was to accelerate and streamline the design cycle alone production system. This idea and its actual implementation led to later application of digitization and virtual design and production assembly systems. Efforts to improve the level of visualization, transparency, output presentation design, but also the effort to comprehensively asses the feasibility of proposed solutions and identify potential conflicts in the proposed system is still in the design phase leads to the development and use of 3D models of objects and complex manufacturing systems (Gregor et al., 2006).

\subsection{The structure of the methodology}

From the initial idea to the application of the principles of workplaces ergonomics has been the gradual application of advanced technologies later developed a methodology for detailed ergonomic design ergonomic workplaces CEIT ErgoDesign. Based on research ergonomics and digital technologies, this methodology is constantly evolving and improving. Its basic structure is shown in Fig. 1. There are fundamental framework highlights three points, namely:

- Getting quality input data.

- Data processing and creation project.

- Proposals to address the workplace with regard to ergonomic requirements.
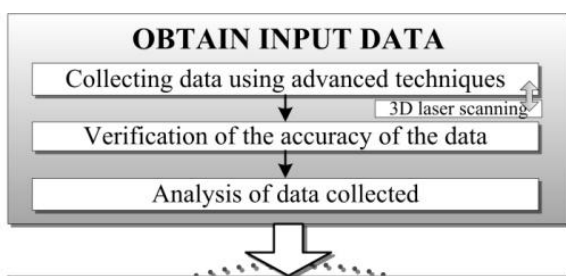

PROCESSING OF EXISTING DATA

Creating a 3D model of the workplace
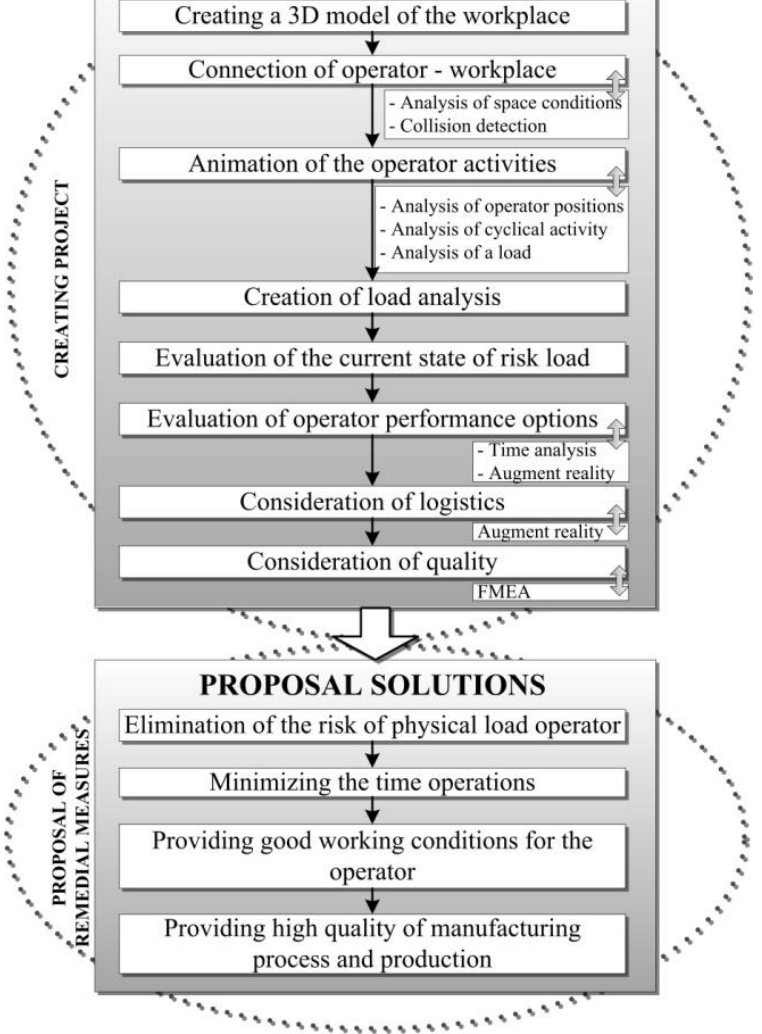

Fig. 1 Methodology CEIT ErgoDesign

The most important new elements of the methodology are:

- 3D laser scanning workstation and its components in order to obtain the exact dimensions of the workplace and to obtain 3D model of the workplace without the need for laborious modeling, 
- Stereoscopic display real operators in the production of stress to facilitate analysis and to minimize disruption in real working conditions.

- Augment reality to support job trainin for operators and new business activities in the field of logistics in the workplace.

\subsection{The use of 3D laser scanning}

3D laser scanning is noncontact focus of spatial information on objects scanned with high accuracy and productivity of work. In our previous projects is currently being used scanner FARO LS $880 \mathrm{HE}$ working range of $76 \mathrm{~m}$. Before the scanning, laser scanner is designed plan, that plan is the reference point and scanning positions, whereby the selected part of the scanned area, where we ergonomic workplace design. Real objects are captured in the form of cloud points and imported into the software FARO SCENE (Fig. 2) with direct data transfer to Microstation in IGES format. The digitization of the need for detailed ergonomic arrangement of workplaces created by elements work in STP format. Digital 3D models are used later in the detailed design layout of workplaces in 3D. An outcome of the module is a list of elements with main dimensions of heights. To support the detailed design is created by assembly of individual handling units and components which are part of the manufacturing precess at work (Furman et al., 2011).

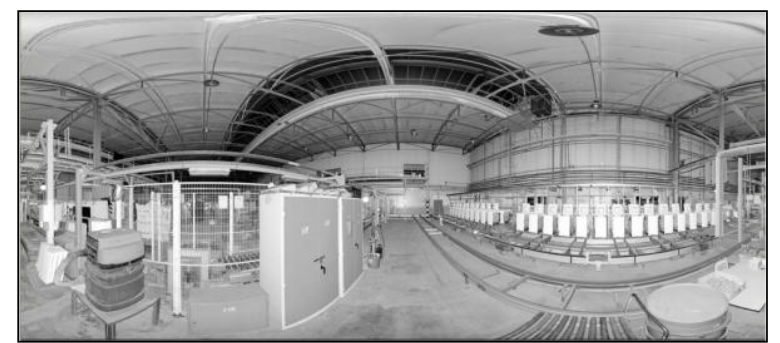

Fig. 2 Demonstration of 3D scanned data

\subsection{Using stereoscopic records}

Stereoscopic records are now one of the newest elements applied to the field of ergonomics. Their use is mainly in the analysis of the real situation in terms of workplace stress analysis operator. Industrial stereoscopic record is realized through a set of cameras from different points at the same workplace. For high quality stereo recording is necessary to take into account many parameters, which are normally available 3D camera does not adjust. The result is a spatial perception of the operator in the workplace, allowing the faithful to follow and analyze the actual movements of the operator. This technology is an alternative to motion capture techniques or the use of the Cave. Its main advantages are (Gašo, 2010):

- Less financial demands on hardware and software solutions.

- Rapid application directly in the production of real work.

- Minimal interference with the production or assembly process.

- Minimum restriction operator supplements work as a helmet, a data suit, sensors, etc.

- Take a real workplace conditions with all the disturbances that inpact on work ergonomics and the like.

\subsection{Using augmented reality (AR)}

Unlike virtual reality, which modeled by means of the whole computer, augmented reality does not replace the real world, but it only added to the selected elements, respectively objects. An appropriate mix of real and virtual objects allows providing a large amount of additional information is provided to maintain the link with the real user environment (Fig.3) (Mirandova et al., 2011).

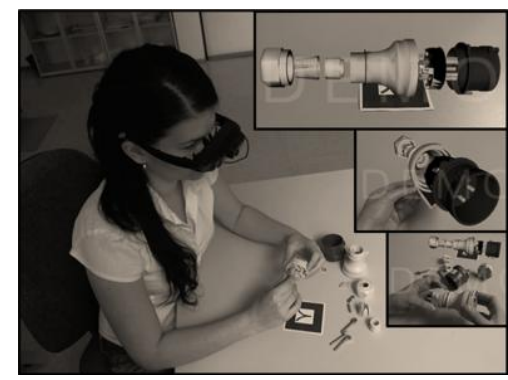

Fig. 3 Installation of an electric plug using AR

The main benefits of practical applications for AR in the ergonomic design of work are mainly:

- Flexibility in testing different variants.

- Increase the speed of testing options.

- Real possibility of combining existing elements of the proposed work with digital elements.

- Effective early elimination of collision situations between man, work equipment and workplace.

- Feedback on the proposed solution of a real operator who, for the 3D model of human absence.

Advantages to create and adopt working practices are:

- Rapid process of acquiring working movements, their sequence and combination.

- Reduce the risk of non-compliance in the work of thanks to the optimal visualization workflow.

- Creation of a standard motion sequence for the optimal pace of work.

- Visual support for the operator of work.

\section{CONCLUSION}

Augment reality, virtual reality, stereoskopy or 3D laser scanning, while not ergonomic tools. Their use for the purpose of ergonomics, however, has benefits in two main areas:

- To increase work efficiency ergonomists to develop solutions.

- Improve working conditions in terms of ergonomics.

Speed and quality of solutions is a competitive advantage. Rapidly changing production needs to react flexibly to new conditions. The biggest pressure is transmitted while the weakest element of the production process, which is typically man. If augment reality operator is able to directly bring new conditions of work in order to have the opportunity to get acquainted with them, without him there was a risk to health. Subjective information from the implementation of our work is not yet able to provide a virtual no man's model. Therefore, the application of augment reality is of unique importance not only for humans but also executing work for the company in the form of better output in less time and with greater efficiency.

\section{REFERENCES}

Furmann, R. \& Krajčovič, M. (2011) Modern approach of 3D layout design, In Transcom 2011, p. 43-46, University of Žilina, ISBN 978-80-554-0370-0, Žilina

Gašo, M. (2010) Ergonomics of stereoscopic recordings, In Ergonomics 2010, p. 106-110, Slovak ergonomics association, ISBN 978-80-970588-6-9, Žilina

Mirandová, G. \& Krajčovič, M. (2011) Use of augmented reality in industrial engineering, In Transcom 2011, p. 193196, University of Žilina, ISBN 978-80-554-0370-0, Žilina

Gregor, M. et al. (2006) Digital Factory, SLCP, ISBN 80969391-5-7, Žilina

Hatiar, K. (2008) Ergonomics and technology effectiveness, Hochshule FH Anhalt, ISBN 978-3-86011-020-1, Köthen 